\title{
Physic-Mechanical Characterisation of Materials Clay Mayo-Tsanaga in the Far North Region of Cameroon
}

\author{
E. Ngale Haulin ${ }^{1}$, F. Tchangnwa Nya ${ }^{1,2, *}$, C. Kabe ${ }^{1}$, B. Touogam Touolak ${ }^{1}$ \\ ${ }^{1}$ Department of Materiel Processing, Architecture and Habitat, Higher Institute of the Sahel \\ ${ }^{2}$ Department of physics Faculty of Sciences University of Maroua \\ *Corresponding author: nyafridolin@yahoo.fr
}

Received November 22, 2014; Revised December 15, 2014; Accepted December 23, 2014

\begin{abstract}
The Cameroon Development challenges are inseparable from the production of large basic infrastructure and building quality homes. To face this challenge, it is essential to promote better local and regional natural resources. The present work aims to contribute to the development of clay resources, in order to develop the production of sustainable building materials, and energy-efficient premises in the northern parts of Cameroon. The research is based on the study of clay materials for little greedy mudbrick energy and respecting the local housing. The physico-mechanical characterisation of clay materials will choose best raw materials for use in the manufacture of bricks suited to homes in the Sahel. This scientific work and leads to value of mineral resources (clay) for the ecohousing design in northern Cameroon. Along these lines, the following approach was adopted: We started with field work that consisted mostly to test campaigns; then we conducted laboratory studies. These studies have focused on the physical and mechanical tests. It is especially a question of determining the natural water content, the Atterberg limits, the particle size of the appropriate materials, the equivalent test sand, the Proctor test, and finally the CBR test. In a perspective of sustainable local development, this scientific work focuses on the development of industrial mineral clay should therefore serve as an interface relating to existing major cooperation projects between Cameroon and the World Bank.
\end{abstract}

Keywords: characterisation, valuation, clay, industrial mineral substances, ceramic industry, North Cameroon

Cite This Article: E. Ngale Haulin, F. Tchangnwa Nya, C. Kabe, B. and Touogam Touolak, "PhysicMechanical Characterisation of Materials Clay Mayo-Tsanaga in the Far North Region of Cameroon.” American Journal of Materials Science and Engineering, vol. 2, no. 4 (2014): 68-72. doi: 10.12691/ajmse-2-4-4.

\section{Introduction}

In a perspective of sustainable local development, this study focused on the characterisation of clay materials in the Mayo-Tsanaga for valorisation in the ceramics industry. It has the advantage of contributing to the promotion of local building materials while improving the quality of artisan ceramics produced. Sediment used in this study comes from the area of the Far North Cameroon (Mayo-Tsanaga) [1-9].

As part of this work, we performed a particle size characterisation, textural, physics and mechanics of this clay to assess their potential in ceramic industry. Clay Mayo Tsanaga is plastics. Virtually all of these materials consists of particles of diameter less than $16 \mathrm{~mm}$ with about $40 \%$ of particle size less than or equal to $0.005 \mathrm{~mm}$. According to the classification "Highway Research Board" more than $35 \%$ of particles have a diameter $\leq$ $80 \mu \mathrm{m}$ where the class A-7-6. The group indexes range from (2) to (9). Clay materials of the study area are sandy clay Class A-7-6 (5) and A-7-6 (9); and clayey sands Class A-7-6 (2). The clay fraction sample of MayoTsanaga is dominated by illite and kaolinite with chlorite varying proportions. These three types of clay minerals are largely responsible for the favorable properties of ceramic clay studied samples.

This study is an important contribution to scientific knowledge of the properties of clay materials MayoTsanaga. The study has the advantage of contributing to the promotion of local materials and encourages the creation of small and medium enterprises in different sectors using the clay material as feedstock. One can have an idea about the properties of the clay material, and thus so anticipate potential industrial sectors valuation.

\section{Materials}

To carry out such a study, it requires the use of sophisticated and appropriate materials. This includes various identification devices, geotechnical apparatus such as: Casagrande, mold and Proctor lady, an oven, an electronic scale, standard sieves, chronometers. We also felt the need to use small equipment for field test dug up including: a measuring tape, a digital camera, bags and plastic bags, a field notebook, a pen, a pickaxe, an auger manual, GPS, and vehicle brand land Rover.

\section{Methods}


As part of this research, we opted for a methodology that first involved a review of the literature on the topics that are closely related to our study. Next, we conducted a prospective study of clay deposits in the Mayo-Tsanaga, as well as identification of geotechnical tests such as: natural water content, sand equivalent test, sieve analysis, Atterberg limits, Proctor normal modified, and Californian Bearing Ratio test. For test results obtained in the laboratory, we have formulated strategies for profitability and valuation of clay minerals of the Far North Region Cameroon.

\subsection{Location of the Study Area}

Our study area is the mayo located in the town of Maroua III. However, it's crossed by two (02) other Mayos: the Kaliao and the Tsanaga. Located at the southern entrance of Maroua, Bridge Makabaye of MayoTsanaga is a strategic point. As the culmination of passage on the economic link between the port of Douala, the Far North Region and Chad. The construction of Makabaye Bridge was also part of the overall project of reconstruction works of art on the road of interest in the region [17].

\subsection{Geographic Coordinates of Sampling Points}

Table 1 shows the distances between wells, sample codes, and the coordinates of different sampling points.

Table 1. Geographical coordinates of the sampling points of the Mayo-Tsanaga

\begin{tabular}{|c|c|c|c|c|}
\hline $\begin{array}{c}\text { Sampling } \\
\text { wells }\end{array}$ & Codes & \multicolumn{2}{|c|}{$\begin{array}{c}\text { Distances } \\
\text { between wells }\end{array}$} & Geographic coordinates \\
\hline 1 & E1 & 1 at 2 & $200 \mathrm{~m}$ & $\begin{array}{c}10^{\circ} 34^{\prime}, 55,92^{\prime \prime} \mathrm{N} \text { and } \\
14^{\circ} 18^{\prime \prime} 27,81^{\prime \prime} \mathrm{E} \text { and } 404 \mathrm{~m}\end{array}$ \\
\hline 2 & E2 & 1 at 3 & $300 \mathrm{~m}$ & $\begin{array}{c}10^{\circ} 34^{\prime} 51,48^{\prime \prime} \mathrm{N} \text { and } \\
14^{\circ} 18^{\prime} 9,7^{\prime} ' 1 \mathrm{E} \text { and } 405 \mathrm{~m}\end{array}$ \\
\hline 3 & E3 & 2 at 3 & $250 \mathrm{~m}$ & $\begin{array}{c}10^{\circ} 34^{\prime} 55,45^{\prime \prime} \mathrm{N} \text { and } \\
14^{\circ} 18^{\prime} 1,62^{\prime \prime} \mathrm{E} \text { and } 404 \mathrm{~m}\end{array}$ \\
\hline
\end{tabular}

\subsection{Description of the sampling wells}

The sample in our study area was carried out in three wells (E1, E2, E3) drilled manually using a hand auger. However, it should be noted that the E3 well is located in an artisanal mining area of clay materials. The image of Figure 1 clearly illustrate some sample points, and cutting all the drilled well with their respective depths.

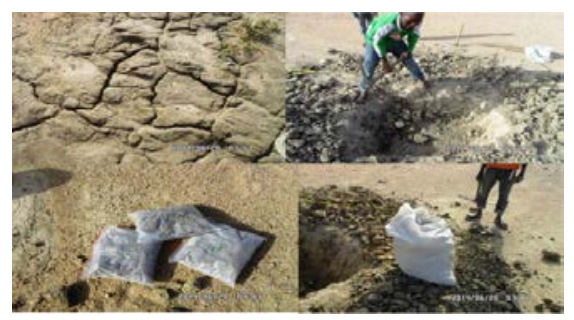

Figure 1. Plate few frames of sampling

\subsection{Stratigraphic Wells Sampling Mayo-Tsanaga}

It may be remarked that a depth of 1 meter, is the presence of sandy clay containing small proportion of organic matter. Much beyond this depth, the gray clay tends to become less sandy, and therefore more plastic $[11,12,14,16,25,26]$.

\subsection{Physic-mechanical Laboratory Tests}

It will be discussed in this section of literature review the works that deal with the physic-mechanical tests, of materials clay in the laboratory [14,18,21,23-33].

\subsubsection{Natural Water Content}

The determination of the natural water content is based on the following formula:

$$
\mathbf{W}(\%)=100\left(\mathbf{P}_{\mathbf{h}}-\mathbf{P}_{\mathbf{s}}\right) / \mathbf{P}_{\mathbf{s}}
$$

With $\mathrm{P}_{\mathrm{h}}$, the weight of the soil sample in its natural state; Ps, the weight of the soil sample after heating in the oven at $105^{\circ} \mathrm{C}$ for 24 hours. This is the dry net weight that is equal to the difference of the total dry weight of the tare weight used [14,18,21,23-33];

$$
\mathbf{P}_{\mathbf{h}}-\mathbf{P}_{\mathbf{s}}=\text { weight of water }
$$

\subsubsection{Equivalent Sand}

Produced on the fraction of materials passing through the sieve of $5 \mathrm{~mm}$, the sand equivalent test reflects the overall quantity and quality of elements contained in the finer fraction, expressing a volumetric ratio of said conventional elements sand and finer (clay, for example). Depending on the value of sand equivalent (ES) obtained, the soil is well described [14,18,21,23-33].

\subsubsection{Size Analysis by Dry Sieving and Sedimentometry}

The particle size analysis is used to determine the distribution of the particles of greater than or equal to 80 microns following a soil dimensions. The test is to draw a curve that shows the size evolution of the percentages by weight of sieves (or refusal) accumulated based mesh openings of the sieves. From the grading curve will be assigned a schedule for a first identification of the soil [14,18,21,23-32].

\subsubsection{Atterberg Limits}

The test consists of determining the liquid limit $\mathrm{W}_{\mathrm{L}}$, which marks the passage of a sample of the plastic state to the liquid state. And the plastic limit $\mathrm{W}_{\mathrm{P}}$, which corresponds to the passage of the sample from the solid state to a plastic state shrinkage. Finally, the plasticity index, which provides information on the extent of the plastic field soil [14,18,21,23-33].

\subsubsection{Proctor Test}

The principle of the test consists in wetting Proctor multi soil and water contents according to the compacting method and a conventional energy. For each of the water content values considered, it is determined the dry density of the soil and the variation curve of this density is established as a function of the water content [14,18,21,23-33].

\subsubsection{Californian Bearing Ratio Test}

This is a dimensionless number expressing in percentage, the ratio of pressure producing a given material studied in one hand driving, and type material on the other. It is carried out on standard samples, saturated or unsaturated, or reworked intact and in place in the field. 
Generally, the first material is completely dried in an oven $105^{\circ} \mathrm{C}$. The material is then fed in powder form or by disaggregating the clumps with a hand roller, when clay is, by passing it through a ball mill. The material is compacted in five layers of equal thickness. Each layer receives 55 shots lady standard well distributed over the entire surface. Once compaction is completed, is removed upward, and then the sample is leveled according to the higher level of the mold with the screed plate [14,18,21,23-33].

\section{Results and Discussion}

This section will present comments on the results of the main geotechnical, physic-mechanical laboratory tests.

\subsection{Results of Geotechnical and physic- mechanical Laboratory Tests}

\subsubsection{Natural Water Content}

The main results obtained during the test are summarised in Figure 2.

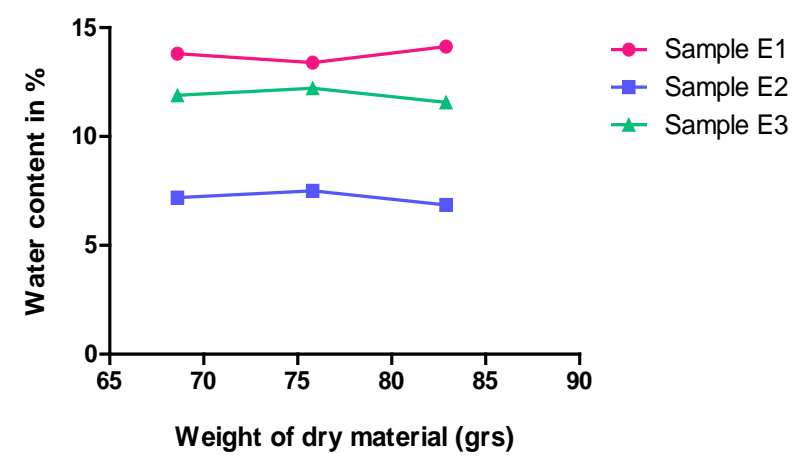

Figure 2. Measures of natural water content

It's clear from these analyses that the average water content in the natural state is $10.9 \%$. This low and variable natural water content can be linked to the amount of fines or clay content elements in the samples analysed. On the other hand, the climate of the region during the sampling period [14,18,21,23-33].

\subsubsection{Equivalent Sand Test}

Figure 3 shows the results obtained when measuring the equivalent of sand for the two tests taken from each sample watercourse Mayo-Tsanaga in Maroua.

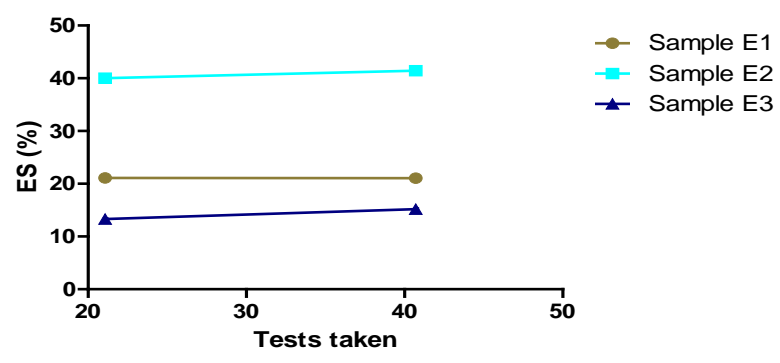

Figure 3. Measurement of Equivalent sand

At the end of this test, only E1 and E3 are samples plastic flooring that is to say clay. While Sample E2 in itself is a non-plastic soil containing very little clay [14,18,21,23-33].

\subsubsection{Size Analysis by Dry Sieving and Sedimentometry}

Figure 4 and Figure 5 gives an overview of particle size proportions by sieving and clay materials sedimentometry Mayo Tsanaga.

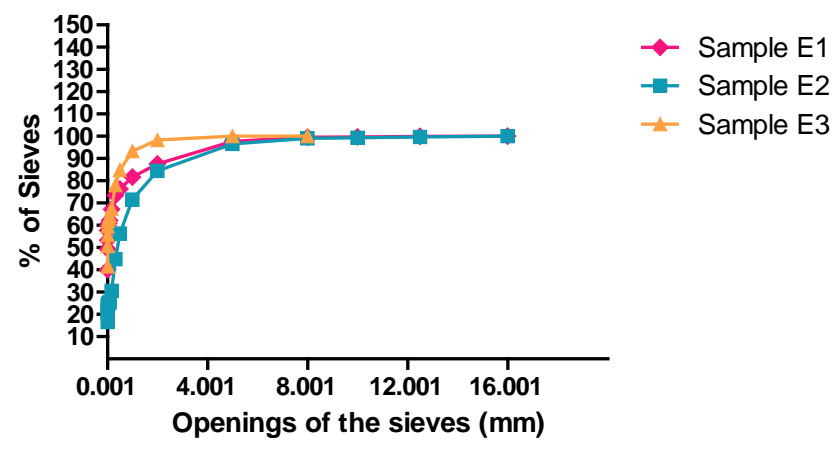

Figure 4. Particle size proportions by sieving

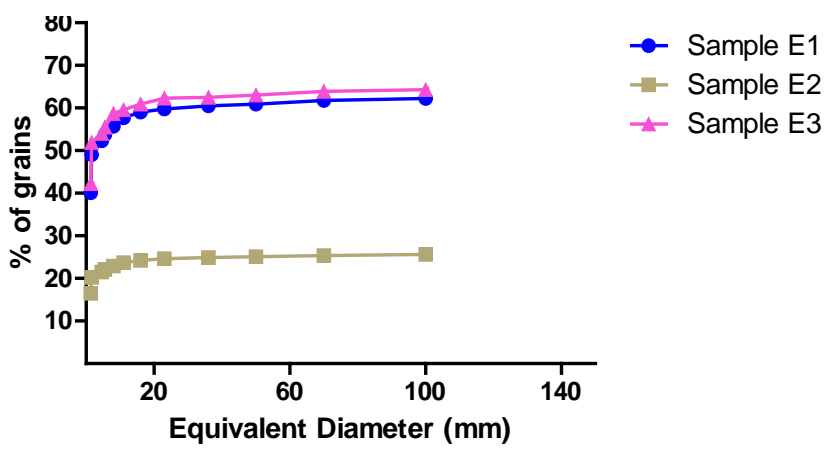

Figure 5. Results of densitometry analysis of E1, E2 and E3

Examination of Figure 4 and Figure 5 show the fine character of Clay materials in Mayo-Tsanaga. Emphasises the characterrisation of the non-uniformity particle size and spread of clay material.

They also present the results of particle size analysed by sieving and sedimentometry which allows clearly realising that clay materials of Mayo-Tsanaga consist only of particles less than $12.5 \mathrm{~mm}$. These figures clearly suggest the percentage of passers sieve of $0.001 \mathrm{~mm}$ which is $40 \%$ for samples E1 and E2, and $16.5 \%$ for those of E3. It is also noted that these clay materials are made from more than half of the particles of sizes greater than $0.5 \mathrm{~mm}[10,19,20,22,23]$.

\subsubsection{Atterberg Limits}

Figure 6 presents the results of Atterberg limits test for materials clay of Mayo-Tsanaga.

WL: Liquid limit Wp: Plastic limit Ip: Plasticity index

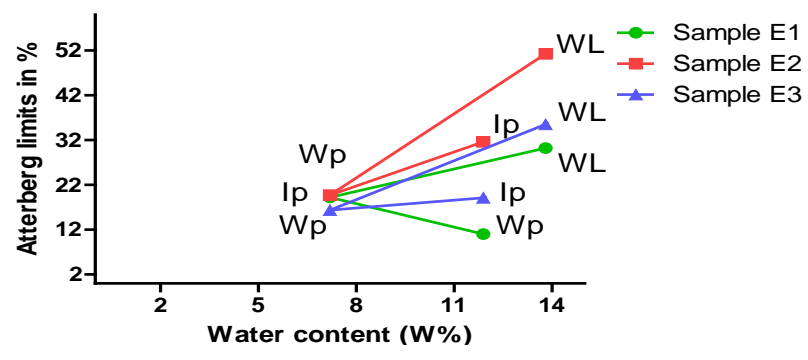

Figure 6. Results of Atterberg Limits Test 
It's noted that studied clay materials are plastic from the plasticity index obtained. These materials contain a large proportion of clay. The difference in soil plasticity is due to the presence of fine particles contained in the samples. The results of particle size analysis and Atterberg limits of those from the HRB classification method to classify the soils of Mayo-Tsanaga area. The studied soil show that is sandy clay class A-7-6 (5) and A-7-6 (9), respectively, for samples E1 and E3. Regarding the sample E2, it is a sandy loam of class A-7-6 (2).

The HRB classification appears to be more than $35 \%$ of grains which has a diameter $\leq 80$ microns, with the class A-7-6. The numbers in bracket represent the index of the group. These indexes are group based of the liquid limit $\mathrm{W}_{\mathrm{L}}$ and the plasticity index Ip. Unlike group index confirms our observations in the field where E2 sample contains more sand [10,11,12,13,15,20,22,23,33].

\subsubsection{Proctor Test}

The results obtained after this test, allow us to represent the curves of dry density variation as a function of water content.

The modified Proctor was used to determine the optimum water content $\left(\mathrm{W}_{\theta \mathrm{p}}\right)$ and maximum dry density $(\gamma d)$ at a fixed energy compaction.

Thus we will sample $1 \mathrm{Wop}=20,4 \mathrm{kN} / \mathrm{m}^{3}$ et $\gamma \mathrm{d}=8,3 \%$. For sample $2 \mathrm{Wop}=21,1 \mathrm{kN} / \mathrm{m}^{3}$ and $\gamma \mathrm{d}=6,6 \%$. And finally, for sample $3 \mathrm{~W}_{\text {op }}=19,6 \mathrm{kN} / \mathrm{m}^{3}$ et $\gamma_{\mathrm{d}}=10,7 \%$.

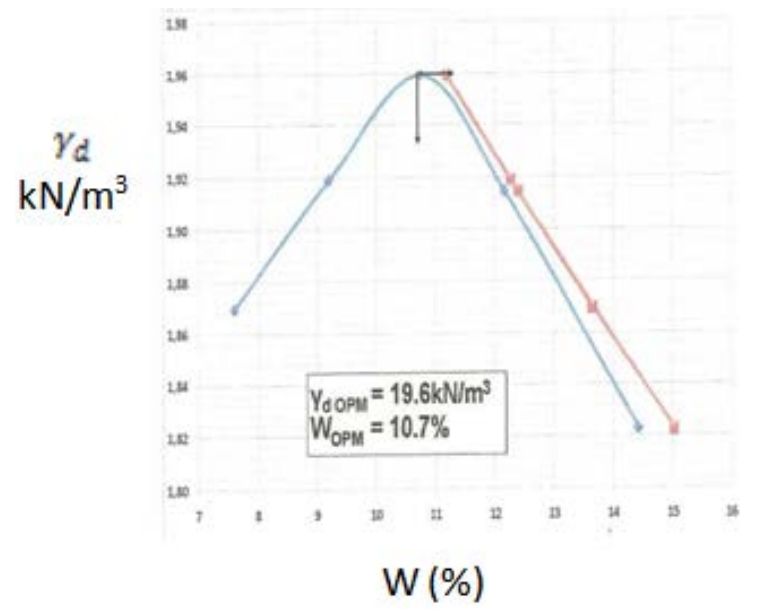

Figure 7. Proctor Curve of sample E1

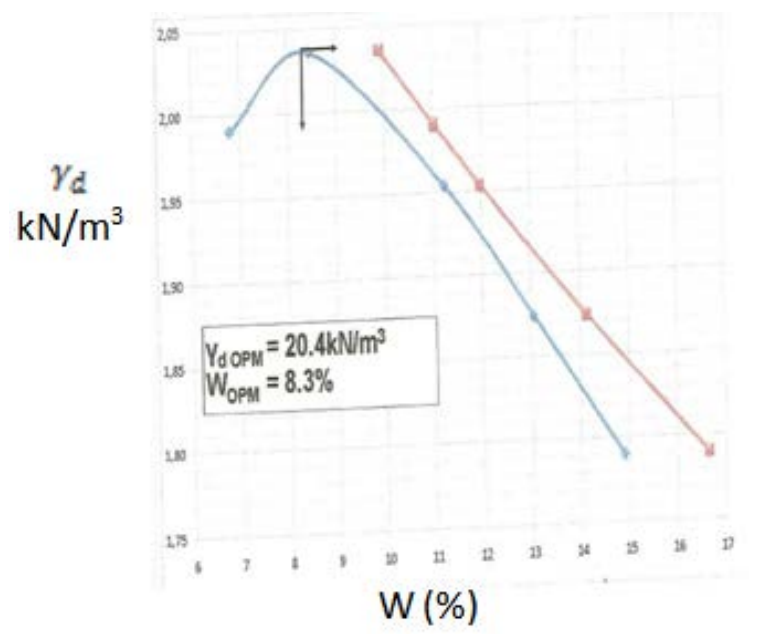

Figure 8. Proctor Curve of sample E2

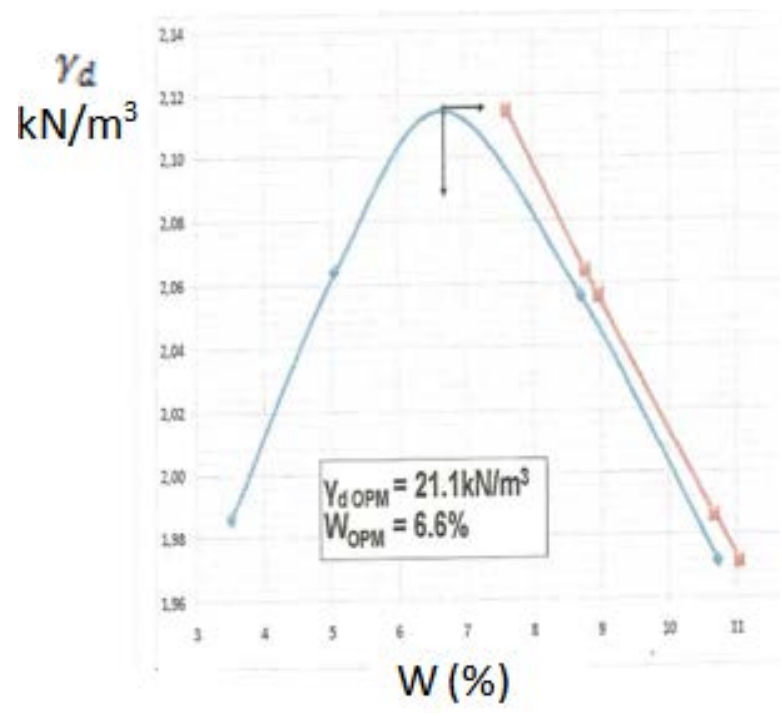

Figure 9. Proctor Curve of sample E3

It's therefore inferred that soil studied is sandy clay [10,11,12,13,15,20,22,23,33].

\subsubsection{Californian Bearing Ratio Test}

The results obtained allow us to represent the followings curves of dry density variation on CBR values.

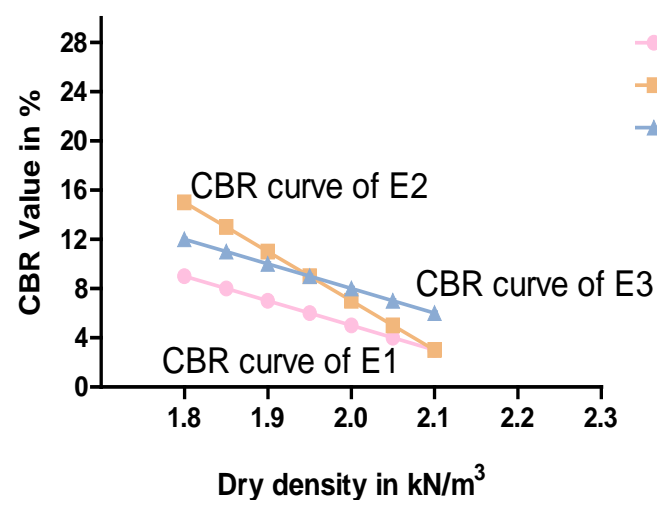

Figure 10. Curve Californian Bearing Ratio of sample E1, E2 and E3

\section{Conclusion}

Because of its various properties, clay has been used since antiquity in the manufacture of pottery rudimentary. Nowadays, the use of clay materials is booming in the industrial construction in the ceramics [6,8,9,11,13,18,34,35,36].

In a sustainable local development, this work has major objective to make the valorisation of clay materials in the far nor then Cameroon in general and the mayo Tsanaga area in particular.

So it has a double interest: scientific and industrial, and contributes to the development of local materials. As prospects, we offer this work for a sustainable and integrated management of industrial mineral resources in Cameroon, and the Far North Region in particular, would be part of the organisation related data form of mapping using the tools of Geographical Information System (GIS). And secondly, a heat treatment of clay materials studied would better understand the thermal properties and mechanical behaviour after heating for best” using and profitability. 


\section{References}

[1] RICAL K. NABIL R., Muzahim AM., "Influence-based cements local mineral additives on the mechanical properties of mortars and concretes" 22nd academic meetings in civil engineering, France, 2004.

[2] FESTA J., G. DREUX, New Guide of concrete and its components, Paris, editions Eyrolles, 2007.

[3] DUPAIN R., Aggregates, soils, cement and concrete, Paris, Edition Casteilla 2000.

[4] CHAHIDI ELOUAZZANI D. Physico-chemical characterization and optimization in construction and public works of ash from the incineration of paper mill sludge. PhD thesis, University of Lyon, in 2005.

[5] BIBI M., CHIKOUCHE MA, AIT TAHAR K., "Influence of sandstone clay additions and / or muddy on the properties of cementitious materials" Materials newspaper and technique2008.

[6] A. Bessa, Bigas JP, JL Gallias., Evaluation of the binding contribution of mineral additions to the porosity, compressive strength and durability mortars, academic meetings 22nd Civil Engineering 2004, P 1-8 .dropoff window.

[7] U. Chinje Melo, Billong N., pozzolanic activity waste bricks and tiles cooked, African Journal of Science and Technology (AJST), Science and Engineering Series Vol. 5, No. 1, 2004, P 92-100.

[8] K. Sobolev, TR Naik, Performance as a factor for sustainability of the cement industry, Report No. CBU-2005-17, Rep-588, August, 2005.

[9] Chahidi Elouazzani D. Physico-chemical characterization and optimization in construction and public works of ash from the incineration of paper mill sludge, Ph.D. thesis, National Institute of Applied Sciences in Lyon, 2005, P 18-21.

[10] A. Assifaoui, 2002. Study of the stability of slurries based local clays, application to industrial ceramics formulations. Thesis. University Hassan II Ain Chock.

[11] El Yakoubi N., 2006. Potential use of Moroccan clay in the ceramic industry: the case of deposits and Jbel Kharrou Benhmed (western Moroccan Meseta). Thesis University Mohammed VAgdal.

[12] CIRAC, P. (1987), The Basin south western Rif the upper Neogene. Evolution of the sedimentary dynamics and palaeogeography during a filling phase. PhD Thesis of State, No. 837. University Bordeaux I. 285 p.

[13] EL YAKOUBI. N (2006) Potential use of Moroccan clay in the ceramic industry. For deposits of Jbel Kharrou and Benhmed (Western Moroccan Meseta). Thesis ès Sciences. University Mohammed V Agdal. 212 p.

[14] FEINBERG H. (1986), tertiary series of external areas of the Rif (Morocco) biostratigraphy, paleogeography and tectonic overview; Notes and memoirs of the Geological Survey of Morocco; \# 315.

[15] FLINCH, J. (1993) Tectonic Evolution of the Gibraltar arc. PH. D. Thesis, Rice University, Houston, 381 p.

[16] Litto, W. (2001). Contribution of reflection seismic and well logs to the study of the geodynamic evolution of Neogene basin oil potential. Example of the Northern margin of Gharb Basin (foreland of the Rif, Morocco). Thesis, University Mohammed V, Rabat, Morocco, 212P.

[17] MAYCHOU. S (2009) Morphostructural Study and GIS mapping Rharb Septentrional and Prerif (Morocco). Seismotectonic analysis and modeling of the deformation in the region of Moulay
Bousselham. Thesis es Sciences. Univ Chouaib Doukkali Jadida University Bordeaux 1, Bordeaux. 197 p.

[18] Sadik. C, EL IMRANI. I \& ALBIZANE. A (2012), Influence of chemical and mineralogical kind of clay and manufacturing process on the quality of ceramic tiles. MATEC Web of Conferences 2, Vol. 01016.

[19] WERNLI, R. (1987). Micropaléontologie Neogene Sticky patches of northern Morocco and systematic description of planktonic foraminifera. Notes and Mem. Serv. Geol. Morocco, 331, 270 p.

[20] C. Bich, Contribution to the study of thermal activity kaolin: Evolution of the crystallographic structure and pozzolanic activity, PhD, National Institute of Applied Sciences in Lyon, 2005, P 4445.

[21] Ikaya, (2004), Technical Specifications. Treatment center and factory Salé, Morocco. pp. 1-4.

[22] BARON J., JP OLLIVIER, concretes, data bases and for their formulation, Paris, Eyrolles, 1997.

[23] A. Allawi, Haimeur J., I. El Amrani, M. Ahmamou 2005 chemical-mineralogical and technological characterization of red clays Khémissat: interest in the clay industry. Specifications of research, series and Sci Tech (Geology), (6), 7-26.

[24] F. Guerraoui, Zamama Mr. and Ibnoussina, M., 2008. mineralogical and geotechnical characterization of clays used in ceramics in Safi (Morocco). African Journal of Science and Technology, Science and Engineering Series (9) 1, 1-11.

[25] ASTM C674-88, Standard test methods for flexural properties of whiteware ceramic materials, Volume 15-02, Glass and ceramics.

[26] ASTM C 326-03, Standard test method for drying and firing shrinkages of ceramic whiteware clays, 15-02, Verre et céramique.

[27] ASTM C674-88, Standard test methods for flexural properties of ceramic whiteware materials, 15-02, Verre et céramique.

[28] ASTM (DIN 51006), Standard test method for thermogravimetric analysis (TGA).

[29] K. Traoré, Blanchart Ph., JP and Jernot Gomina M., 2007. physicochemical and mechanical characterization of ceramic materials obtained from a kaolinitic clay from Burkina Faso, CR Chemistry 10, 511-517.

[30] ASTM C373-88, Standard test method for water absorption, bulk density, apparent porosity, and apparent specific gravity of fired whiteware products, Volume 15-02, Glass and ceramics.

[31] ASTM C373-88, Standard test method for water absorption, bulk density, apparent porosity, and apparent specific gravity of fired whiteware products, 15-02, Verre et céramique.

[32] Baccour ZGHAL. H, Medhioub. M \& MHIRI. T (2011), physicochemical and mechanical characterization of ceramic materials obtained from Tunisian clays. Glass, Ceramics \& Composites, Vol.1, Vol. 2, pp 25-33.

[33] HOUHOU MN, MEZGHICHE B., "Influence of adding pozzolan on the mechanical behavior of cement paste", 2nd Maghreb Symposium in Civil Engineering, Biskra Algeria 2002

[34] ASTM C 326-03, Standard test method for drying and firing shrinkages of ceramic whiteware clays, Volume 15-02, Glass and ceramics.

[35] A. Michot, 2008. thermophysical characteristics of clay-based materials with evolution of heat treatment up to $1400^{\circ} \mathrm{C}$, Thesis, University of Limoges, Fance.

[36] Bouyahyaoui F., 1996. Geological study, mineralogical and technological marl Upper Miocene to Pliocene in the region of Fez-Meknes and Rabat-Salé. Thesis. Université Mohammed VAgdal, Faculty of Science - Rabat. 